\title{
BUILDING A GREEN COMMERCIAL COMPLEX USING GREEN BUILDING MATERIALS AND USING SUSTAINABLE AND SMART RESOURCES- A CASE STUDY
}

\author{
Rameez ut Tauheed \\ Assistant professor, \\ Department of civil engineering, \\ Manav Rachna International Institute of Research and Studies, Faridabad, Haryana- 121004, INDIA \\ Ankit Chawla, Kartik Chauhan, Mohit Tewatia, Vishal Pandey \\ Students, Department of civil engineering, \\ Manav Rachna International Institute of Research and Studies, Faridabad, Haryana- 121004, INDIA
}

\begin{abstract}
Lately there has been a change in perspective in development ventures towards eco agreeable and manageable development and advancement. On account of which numerous structures are planned as eco cordial and reasonable called green structures by alteration of building materials and current innovation through which we will be equipped for diminishing harm to the nature. In the long run, the green structure manages the cost of a significant degree of financial and designing execution, which drives us to the improvement of group of people yet to come.
\end{abstract}

Keywords- Green building, water and energy conservation, green building materials

\section{INTRODUCTION}

A 'green' building is a structure that, in its plan, development or activity, diminishes or wipes out adverse consequences, and might make positive effects, on our environment and indigenous habitat. Green structures save valuable characteristic assets and improve our personal satisfaction. Making structures green is need of great importance it might potentially be venture towards the best ideal use of land, energy and water while guaranteeing a most un-troublesome utilization of characteristic assets inside the way toward establishing a solid climate. It advances preservation of transient non-inexhaustible assets and furthermore the value and subsequently the ecological issues associated with the preparing and transport of these materials.

\section{HIGHLIGHTS OF GREEN BUILDING}

There are a variety of highlights which may make a structure 'green'. These include:
A. Efficient utilization of energy, water and different assets

$B$. Use of environmentally friendly power, as sun based energy

$C$. Pollution and waste decrease measures, and furthermore the empowering of re-use and reusing

D. Good indoor natural air quality

$E$. Use of materials that are non-harmful, moral and reasonable

$F$. Consideration of the climate in plan, development and activity

$G$. Consideration of the class of lifetime of inhabitants in plan, development and activity

$H$. A plan that license transformation to a changing climate

I. Any structure can be a green structure, regardless of whether it's a home, an office, a school, a medical clinic, a public venue, or some other assortment of design, if it incorporates highlights recorded previously.

$J$. Nonetheless, it's important that not all green structures are or should be the indistinguishable. Various nations and districts have a selection of attributes like unmistakable climate conditions, one of a kind societies and customs, different structure types and ages, or wide-going natural, financial and social needs - all of which shape their way to deal with green structure. 


\section{International Journal of Engineering Applied Sciences and Technology, 2021 \\ Vol. 5, Issue 12, ISSN No. 2455-2143, Pages 151-155 \\ Published Online April 2021 in IJEAST (http://www.ijeast.com)}

\section{ALPHATHUM MALL (CONCEPT COMMERCIAL BUILDING)}

\section{III.1 Water conservation}

1. Rain water harvesting

Water collecting is acquiring prevalence coming about in ecopreservation. The greater part of the business structures utilize a significant amount of water and energy in their day by day tasks. Water reaping is old and compelling method of gathering precipitation water during wet season for future utilization reason. The biological benefit of water gathering frameworks for business structures is that there'll be a significant decrease inside the aggregate sum of water utilized from the mains. Surface run-off gathering and housetop collecting are the two primary strategies for water reaping where roof gathering is the most utilized water gathering technique for business structures. The fundamental parts of this technique are: catchment, drain, down take pipes, stockpiling tank, and circulation framework. Catchment region straightforwardly gets the precipitation where drains and down take pipes make the water stream from the catchment surface to the capacity tank which may be put either over the base or beneath the base. At long last, the caught water will be sifted and dispersed to the place of utilization through appropriation framework.

It can give non-consumable water to fulfill different requirements of business building like latrine flushing, clothing, cultivating and so on

- It can decrease mains water framework by 40-half

- It decreases run-off and its destructive effects

- $\quad$ RWH advances both water and energy protection

- The framework is inconvenience allowed to place in, work and keep up

- $\quad$ Are regularly utilized for a few non-drinking purposes

- It likewise helps towards an organization's manageability accreditations

- $\quad$ The truly expanding interest for water might be fulfilled

- $\quad$ It extraordinarily gets a good deal on water bill

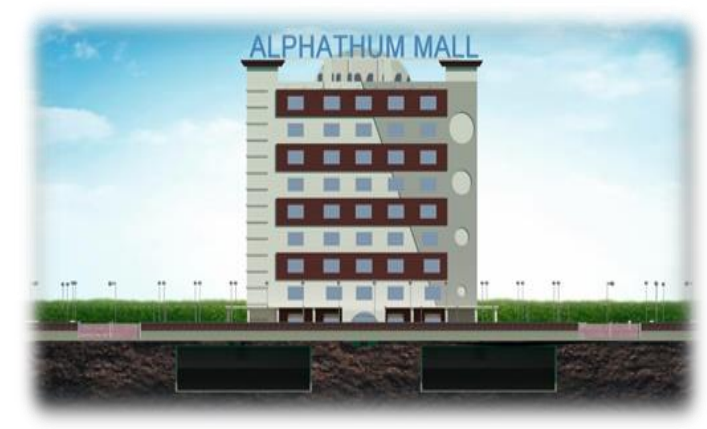

Figure 1: Rainwater harvesting proposed in the system

\section{Usage of treated water}

Like precipitation, treated wastewater may perhaps be utilized for poor quality purposes in structures. The treated water will be held in supplies or lakes. Since the inflow of treated water is nearly consistent (as that the inflow of wastewater), less buffering volume need be made inside the supply.

\section{III.2. Usage of solar power}

1. solar lights in parking

Sun based streetlamps are raised light sources which are controlled by sunlight based boards commonly mounted on the lighting structure or incorporated into the actual shaft. The sun oriented boards charge a chargeable battery, which controls a fluorescent or LED light during the evening. Most sunlight based lights actuate and switch off naturally by detecting outside light utilizing sun oriented board power. Sun based streetlamps are intended to work for the duration of the evening. Many can remain lit for very one evening if the sun isn't into the sky for an all-encompassing timeframe. More seasoned models included lights that were not fluorescent or LED. Sunlight based lights introduced in breezy locales are for the most part outfitted with level boards to improve manage the breezes.

Current plans utilize remote innovation and fluffy control hypothesis for battery the executives. The street lights utilizing this innovation can work as an organization with each light having the capacity of playing out the turning on and off of the organization.

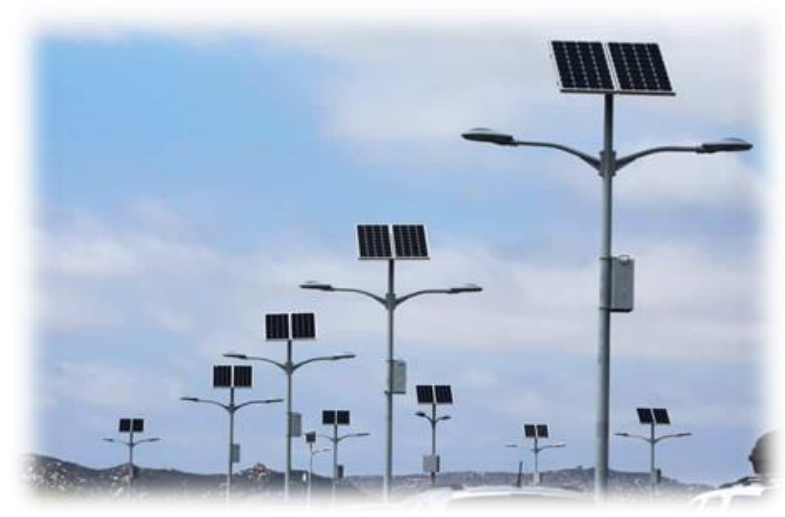

Figure 2: Solar panels on parking lights

2. Solar tiles on roofs benefits

- Relatively simple establishment - These shingles are simpler to introduce than conventional sun oriented boards. The shingles are introduced over new or existing rooftop sheathing, and an electrical technician or 


\section{International Journal of Engineering Applied Sciences and Technology, 2021 \\ Vol. 5, Issue 12, ISSN No. 2455-2143, Pages 151-155 \\ Published Online April 2021 in IJEAST (http://www.ijeast.com)}

roofer wires the units together and into the home's electrical framework.

- $\quad$ Tax-financed -350 sun oriented singles, the normal sum for private applications, could diminish the home's power bill by $40-60$ percent. Moreover, government, state, and adjoining motivators can slice establishment costs down the middle in certain spaces. 27 states and a ton of urban areas offer more motivating forces that are prepared to do additionally bring down sun oriented establishment costs. Look at the Database of State Incentives for Renewable and Efficiency (DSIRE), a free online asset financed by the U.S. Division of Energy, for more data and region explicit motivators.

- $\quad$ Perfect for rooftops effectively under upkeep Eco-cognizant property holders that decide to re-shingle their rooftops in any case are probably going to run over sun oriented shingles particularly engaging. Not exclusively to sun oriented shingles give a wellspring of environmentally friendly power and energy charge cost cuts, yet they additionally give weatherproof insurance to the rooftop.

- $\quad$ Potentially beneficial - Since you don't need paying for both a rooftop and sun oriented boards. Valuing should come in like other top of the line material arrangements. With sun powered shingles, going sun oriented doesn't need to mean slicing connections to your nearby power supply lattice. Most sunlight based shingle frameworks are associated with existing force supplies, which sit once more into it after dusk and on especially overcast days. What's more, if your sunlight based shingle framework produces more force than is needed for the home (especially normal in bright states),

Figure 3: Solar tiles used on a residential building

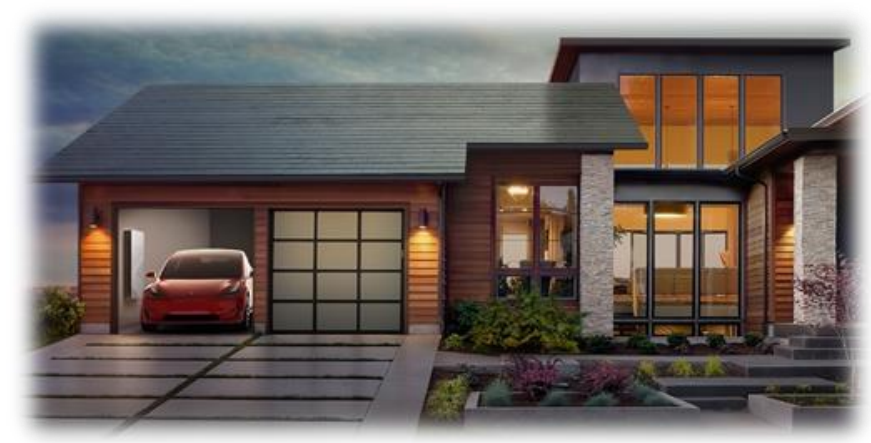

\section{III.3. Usage of eco-friendly building material}

1. Phase change material (PCM) in concrete

PCM limits inordinate temperatures by putting away the excess warmth during the day, and delivering it during the evening. This mirrors the impact of warm mass, which likewise stores heat during the day and deliveries it during the evening. Stage change materials (PCMs) permit a lot of energy to be put away in moderately little volumes, resultant in various least stockpiling media expenses of any capacity ideas.

Furthermore, unique methods of utilizing PCMs are accessible. In structures, these again partition into two gatherings. PCMs can situate in building parts like dividers or roofs, or can be orchestrated in isolated warmth or cold stores. Utilizing PCMs inside structures parts are by and large uninvolved frameworks. The warmth up or cold is put away naturally and delivered when indoor or outside temperatures rise or fall past the stage change point of the material. Utilizing PCMs in independent warmth or cold stores are normally founded on dynamic frameworks. The put away warmth or cold is in control isolated from the actual structure and warmth or cold exchange isn't programmed, however utilized on request.

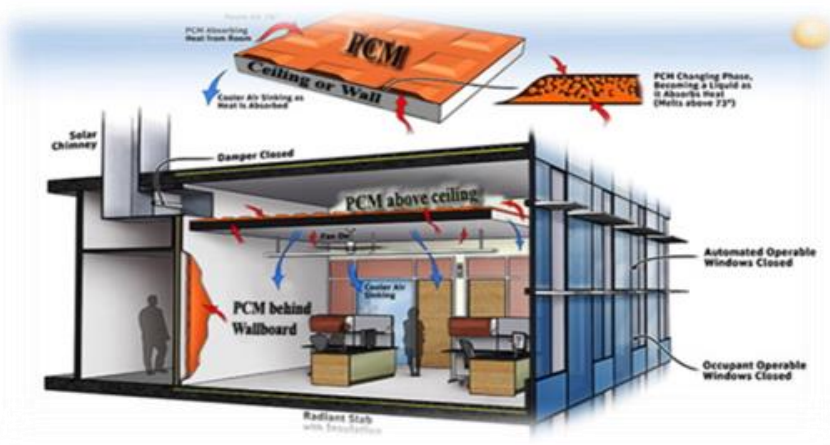

Figure 4: PCM uses

2. Energy-Efficient Glass 


\section{International Journal of Engineering Applied Sciences and Technology, 2021 \\ Vol. 5, Issue 12, ISSN No. 2455-2143, Pages 151-155 \\ Published Online April 2021 in IJEAST (http://www.ijeast.com)}

Engineering glass is a straightforward material that can be most noteworthy affecting material in the structure in respect of letting sunlight based energy comes inside. Sunlight based energy comes in three ranges, bright beams, and apparent light and close infrared beams. Every range has its diverse impact in the structure. Bright range possesses the fundamental duty of blurring the shades of materials and causing a few harms. Additionally the close infra-red has awful impacts of being the principle wellspring of warmth in sun oriented energy. While the apparent light is the principle wellspring of light and a little warmth, as well as causing the light glare inside the structure. Predominantly, the sun based control covering which is applied on the glass surface is the regulator of that energy without disregarding the pretended by the body colored glass on the off chance that it was not satisfactory glass. This covering helps in mirroring a major level of the sun powered beams to outside, and it permit another rate to get inside. For this situation, there will be an acquiring of the noticeable light in restricted rates and forbidding a level of the non-alluring ranges to head inside. The exhibition of such coatings is estimated by one of two factors; the first is the solar warmth acquires coefficient (SHGC) and the other one is the Shading Coefficient (SC). The two variables can be gotten from one another by utilizing the accompanying condition: SHGC = $0.87 \times \mathrm{SC}$. To assess the proficiency of the glass as far as the sunlight based control execution, we need to realize that as long as the two elements are lower they become better. These variables are significant in the condition of computing the inner warm heap of any structure.

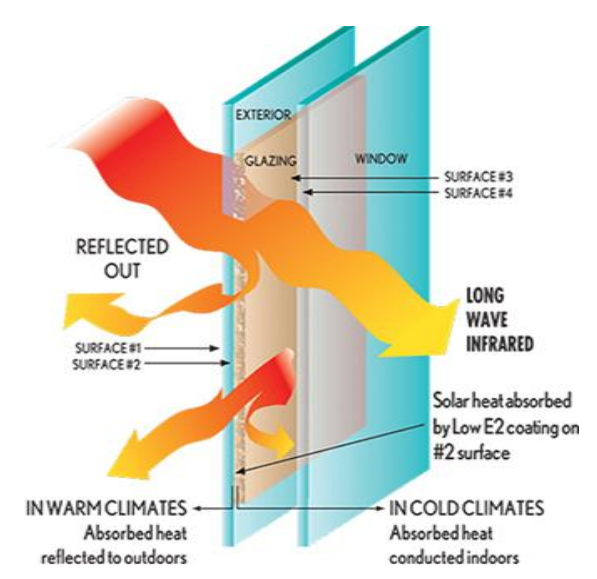

Figure 5: energy efficient glass properties

III.4. Usage of various modern eco-friendly technologies in construction

1. Usage of eco-friendly vehicles.
Transportation provides assistance to economic growth by making accessibility to resources and markets. It also improves quality of life linking persons to employment, health, education, recreation and other amenities. Thus, transportation plays a key role in economic and social development. Nevertheless, it has many spill-over effects such as congestion, safety, pollution and non-renewable resource depletion. The concept of sustainable transportation can be derived from the general sustainable development term that embraces all sectors of human activity. Efficacious and sustainable transportation is a key component to wellfunctioning and civilized societies. Indeed, both developed and developing countries are confronting critical issues in selecting and planning for their future transportation systems when there is a need towards sustainable development that balances accessibility, mobility, protection of human safety and environment. The concept of sustainable transportation is derived from these general terms that imply movement of people and goods in ways that are environmentally, socially and economically sustainable. Vehicle emissions contribute to the increasing concentration of gases linked to climate change. In order of significance, the principal greenhouse gases associated with road transport are carbon dioxide (CO2), methane ( $\mathrm{CH} 4)$ and nitrous oxide $(\mathrm{N} 2 \mathrm{O})$. Road transport is the third largest source of greenhouse gases emitted in the UK, and accounts for over $20 \%$ of total emissions, and $33 \%$ in the United States. Of the total greenhouse gas emissions from transport, over $85 \%$ are due to $\mathrm{CO} 2$ emissions from road vehicles. The transport sector is the fastest growing source of greenhouse gases. Road transport also remains the main source of many local emissions including benzene, 1, 3butadiene, carbon monoxide (CO), nitrogen oxides (NOx) and particulates (PMs). Within urban areas, the percentage of contributions due to road transport is particularly high. In London, road transport contributes almost $80 \%$ of particulate emissions.

Double fuel CNG (Compressed Natural Gas) Backhoe Loader, the JCB 3DX DFI, in India. The new machine can work on $\mathrm{CNG}$ and diesel all the while utilizing the HCCI (Homogeneous Charge Compression Ignition) innovation that serves to 'a significant drop' in particulate emanation; consequently a decrease of proportionate $\mathrm{CO} 2$ discharges, said the organization.

This double fuel CNG Backhoe Loader depends on a similar 3DX model, which is grounded in the Indian market. It offers adaptable fuelling, which will assist clients with supporting far off regions, where a CNG topping off point is inaccessible

\section{CONCLUSION}

This paper center around settling the issues happening because of abuse of characteristic assets by the utilization of materials and assets in such away to make an energy effective green structure minimally affecting climate by decreasing the reliance on regular assets of energy like 


\section{International Journal of Engineering Applied Sciences and Technology, 2021 \\ Vol. 5, Issue 12, ISSN No. 2455-2143, Pages 151-155 \\ Published Online April 2021 in IJEAST (http://www.ijeast.com)}

utilization of power produced from coal and turbines, water, and so forth The development of this structure is finished by utilization of green materials like VOC paint, energy effective glass, LED lighting framework, and so forth which are costlier than the ordinary material promptly accessible yet they will in general save more on upkeep and running expense during its life time. Further, working energy utilization was decreased impressively by depending on sun based energy for warming purposes and by viably putting the windows for inflow of cool air in the structure. Water utilization was diminished impressively by utilizing reused water for watering the plants and keeping up yard and kitchen garden. Uncommon accentuation was given on utilization of green structure material for the development like PCM blocks which were set up from squander materials and furthermore give imperviousness to fire to the structure. The nursery planned is further low on upkeep as its development included broad utilization of characteristic and eco-accommodating materials. This work is a stage towards sound and successful development which limits the loss in the climate.

\section{REFERENCE}

1) G.Kevadiya Ishan , A.Patil Ankush \& N.Waghmode Shruti-Mrudula (2014). Sustainable Construction: Green Building Concept - A Case Study. (page 1)

2) Dieckmann John , Cooperman Alissa (2009).Efficiency, Buildings energy data book. US Program, US Department of Energy, Washington, DC. (page 1)

3) Mishra, S. P., Ali, S. M., Pradhan, A., Mohapatra, P., \& Singh, V. (2013). Increasing energy efficiency in India by the use of green building. International Journal of Renewable Energy Technology.(page 2)

4) Kats, G. (2003). Green building costs and financial benefits. Boston, MA: Massachusetts Technology Collaborative. (page 5)

5) Maini, S. (2005). Earthen architecture for sustainable habitat and compressed stabilised earth block technology. The Auroville Earth Institute, Auroville Building CenterIndia.(page 2)

6) https://elemental.green/10-eco-building-materialsrevolutionizing-home-construction/ (page 3-4)

7) Rasoul Shadnia , Lianyang Zhang \& Peiwen Li b (2015). Experimental study of geo polymer mortar with incorporated PCM.(page 3)
8) Tung-Chai Ling \& Chi-Sun Poon (2013). Use of phase change materials for thermal energy storage in concrete: An overview.(page 3)

9) https://en.wikipedia.org/wiki/Smart_glass . (page 4)

10) http://www.neoakruthi.com/blog/rainwater-harvesting-forcommercial-

buildings.html\#: :text=A\%20rainwater\%20harvesting\%2 0system\%20works, the\%20water\%20in\%20a\%20tank.\&te $\mathrm{xt}=$ The $\% 20$ ecological \%20benefit \%20of\%20rainwater,wa ter\%20used\%20from\%20the\%20mains. (page 2)

11) Adejumo. T.,_(2010). Bikabilty In Metropolitan Lagos: A Conceptualization of Eco Friendly Transportation Alternative.(page 4)

12) Jain, S.S., Parida, M., Mittal, N. (2003), "Environmental Impact Analysis of Transportation Systems in Delhi", ITPI Journal March.(page 4) 